\title{
Analysis of Antimicrobial and Antioxidant Activities of Chenopodium ambrosioides: An Ethnomedicinal Plant
}

\author{
Muhammad Ajaib, ${ }^{1}$ Tanveer Hussain,, ${ }^{1}$ Saleha Farooq, ${ }^{2}$ and Mehrban Ashiq ${ }^{3}$ \\ ${ }^{1}$ Department of Botany, Mirpur University of Science and Technology (MUST), Bhimber Campus, Azad Kashmir, Pakistan \\ ${ }^{2}$ Department of Botany, GC University Lahore, Lahore, Pakistan \\ ${ }^{3}$ Department of Chemistry, University of Gujrat, Gujrat, Pakistan
}

Correspondence should be addressed to Tanveer Hussain; tanveerajk@gmail.com

Received 16 August 2016; Accepted 5 October 2016

Academic Editor: Patricia Valentao

Copyright @ 2016 Muhammad Ajaib et al. This is an open access article distributed under the Creative Commons Attribution License, which permits unrestricted use, distribution, and reproduction in any medium, provided the original work is properly cited.

\begin{abstract}
The antimicrobial and antioxidant potential of Chenopodium ambrosioides L. was explored. Antimicrobial potential was investigated through zone of inhibition and minimum inhibition concentration whereas antioxidant potential of selected plant was evaluated through different techniques, that is, total phenolic contents, total flavonoids content, DPPH assay, ABTS assay, and metal chelating. It is concluded that both parts showed good to satisfactory antimicrobial and antioxidant results. The maximum antibacterial potential is exhibited by bark macerated in petroleum ether against Bacillus subtilis $(33 \pm 1.5 \mathrm{~mm})$ and maximum antifungal potential exhibited by methanol extracts of fruit against Aspergillus niger $(16 \pm 1.5 \mathrm{~mm})$. Aqueous extracts failed to show any activity against selected organisms. The minimum (significant) MIC value exhibited by fruit extract against Staphylococcus aureus was $0.009 \pm 0.02$ at $0.7 \mathrm{mg} / \mathrm{mL}$. Aqueous extracts of bark and fruit exhibited maximum antioxidant potential in all assays except DPPH assay. Petroleum ether bark extract showed maximum \% DPPH value.
\end{abstract}

\section{Introduction}

Plant constituents have broad spectrum in provision of their biological properties and structure and become a source of active natural products. Many disorders such as cancer and cardiovascular diseases are prevented by plants beverages, fruits, and vegetables because they are rich in natural antioxidant compounds. Numerous compounds are present in plants which have diverse mechanism of action that includes some enzymes, protein, and secondary metabolites, for example, carotenoids, vitamins, flavonoids, anthocyanins, and other phenolic components which is the foundation of antioxidant and antimicrobial potential of plant products [1].

In mitochondria, through xanthene oxidase activity and liver mixed function, free radicals are produced as a result of the normal metabolic process and also free radical chain reactions usually occurring as respiratory chain reaction. Moreover, in different circumstances chemical mobilization of the fat stores, for example, lactation, exercise, fever, and infection and yet fasting may result in improved radical activity and damage. If the basic mechanism causes numerous human neurologic and many other disorders, then oxidative injury comes forward. Peroxidation of lipids can be initiated by the oxygen free radical, which in turn stimulates the glycation of protein, inactivation of some enzymes, and modification in the function and structure of collagen basement and a few other membranes, and also play a role in chronic impediment of diabetes [2].

Plant species and numerous herbs were examined and their antioxidant potential was evaluated. It is reported that antioxidant potential is due to some new compounds, that is, flavonoids, coumarins, lignins, anthocyanins, and catechins in plants. The drugs which contain amount of antioxidant compounds are being used for the cure of complex diseases such as diabetes, stroke, atherosclerosis, Alzheimer's disease, and cancer [3].

Chenopodium ambrosioides $\mathrm{L}$. which is a selected plant belongs to family Chenopodiaceae having 103 genera and 


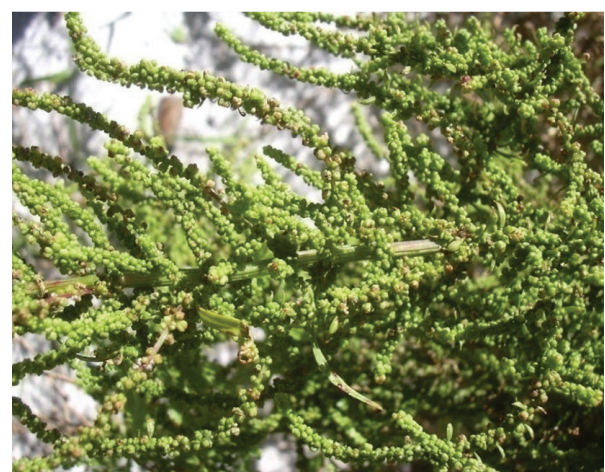

FIGURE 1: Chenopodium ambrosioides.

about 1300 species worldwide. In Pakistan, Chenopodiaceae family consisted of 35 genera and 106 species. The distribution of these genera is mainly in desert and semidesert and along sea shores [4]. Chenopodium ambrosioides L. is strongly aromatic, annual to short lived perennial with erect ascending stem (Figure 1). Leaves of Chenopodium ambrosioides plants are morphologically elliptical and lanceolated. Seeds mostly are horizontal, sometimes oblique, and brown. It is probably originated from tropical America. It is earlier cultivated as medicinal plant and introduced in tropical and subtropical areas of the world, where it is commonly naturalized [5]. C. ambrosioides is an important ethnobotanical plant locally called Gandi Buti in Kotli District and is used as anthelmintic wound healing and constipation (Figure 9) [6].

\section{Materials and Methods}

2.1. Plant Material. The plant Chenopodium ambrosioides L. commonly known as Gandi Buti or Jangli Bhang is collected from Kotli District, Azad Jammu and Kashmir (AJK). The plant material was acknowledged with the valid voucher no. GC. Herb. Bot. 2944 and deposited to the Dr. Sultan Ahmed Herbarium, Department of Botany, GC University Lahore.

2.2. Test Organisms. The bacterial test organisms selected for estimation, that is, Staphylococcus aureus, Escherichia coli, Pseudomonas aeruginosa, and Bacillus subtilis, were attained from the Department of Pathology, Postgraduate Medical Institute, Lahore, for investigation of antibacterial potential of Chenopodium ambrosioides $\mathrm{L}$.

Fungal strains Aspergillus niger and Aspergillus oryzae chosen for the examination of antifungal potential were attained from the Institute of Industrial Biotechnology and Microbiology, GC University Lahore.

The antibiotic standard discs (azithromycin, amoxicillin, ampicillin, and amikacin) and antifungal standard discs (nystatin, tezole, fungivin, and griseofulvin) were consumed to find out receptiveness of microbial specimens.

2.3. Methodology Adopted. The plant specimen Chenopodium ambrosioides L. primarily is dispersed into its parts, that is, bark and fruit, and then shade dried for 20-30 days at room temperature. Finally, desiccated plant material was crushed and macerated.
2.3.1. Maceration of the Plant Specimen. During static state maceration, quantity of crumbled plant precisely was weighed and referred to impenetrable glass jar and was consistently dipped in respective solvent and positioned aside with continuous agitation at room temperature for interval of 8 days. Subsequently, after the achievement of the time, the constituents who are present in glass jar were subjected to filtration by means of filter paper. The extract of plant material was preserved in glass vial; solid filtrate was dried out for about 20 minutes and similar procedure was used for other solvents. The solvents which were used for maceration include petroleum ether (PE), chloroform (Chl.), methanol $(\mathrm{MeOH})$, and water (Aq.). The maceration scheduled from nonpolar to polar solvent and solvents was applied with their polarity gradients. Ultimately, extracts were concentrated and dehydrated by means of rotary evaporator as well as lyophilized concentrated extract which is obtained and stored at $20^{\circ} \mathrm{C}$

The physical analysis of plant extracts considered its colour, appearance, and texture and percentage (\%) yield before further scrutiny was conducted. The percentage (\%) yield was calculated by using the formula which is given below:

$$
\begin{aligned}
& \text { Percentage (\%) Extraction yield } \\
& =\frac{\text { Wt. of plant extract }}{\text { Wt. of initial plant sample }} \times 100 \text {. }
\end{aligned}
$$

2.4. Evaluation of Antimicrobial Activity. Antimicrobial potential of Chenopodium ambrosioides L. was estimated by taking into consideration the following methodology.

2.4.1. Preparation of Plant Sample. Collected plant samples were weighed as to take $0.2 \mathrm{~g}$ and convert it into a glass vial and make final volume up to $20 \mathrm{~mL}$ through the subsequent solvent. The glass vials have concentration of $\mathrm{mg} / \mathrm{mL}$ and are preserved at $20^{\circ} \mathrm{C}$.

2.4.2. Preparation of Medium. Investigation of antimicrobial potential of the plant macerates was carried out through gram-positive and gram-negative bacteria which are cultured on the nutrient broth agar medium. The medium was prepared according to Cruick-Shank et al. [7]. The fungal specimens are cultured on PDA medium applied by Johansen [8].

2.4.3. Preparation of Medium Plates. $15-20 \mathrm{~mL}$ of medium was poured to every petri plate and medium containing plates covers were placed at particular position and preserved with the cling film and were stored in the uncontaminated location at room temperature until consumption.

\subsection{Preparation of Inoculums}

2.5.1. For Bacterial Strains. $20 \mathrm{~mL}$ of sterilized nutrient broth poured into test tube and bacterial strains were put into it 
under aseptic conditions. Subsequent to inoculums grounding, the test tubes were positioned in the incubator for 24 hours at $35 \pm 2^{\circ} \mathrm{C}$ and labeled properly.

2.5.2. For Fungal Strains. Petri plate containing potato dextrose agar medium was streaked with the fungal strains under aseptic conditions. After that, petri plates having inoculums were sealed with cling film positioned in the incubator for 48 hours at $25 \pm 2^{\circ} \mathrm{C}$ and labeled properly.

\subsection{Adjusting the Turbidity of the Inoculums}

2.6.1. For Bacterial Inoculums. With the help of 0.5 barium chloride McFarland turbidity standard, we accustomed the turbidity of bacterial inoculum to $1.5 \times 10^{8}$ colony forming units $(\mathrm{CFU}) / \mathrm{mL}$.

2.6.2. For Fungal Inoculums. In order to sustain the turbidity of inoculums, 4-5 colonies from the 48 -hour fungal culture dish were subjected to $10 \mathrm{~mL}$ saline solution, that is, $0.9 \% \mathrm{NaCl}$ solution, and its consistency was homogenized by employing $0.5 \mathrm{McFarland}$ density standard. For fungal samples the density should be within the series of $1 \times 10^{3}$ to 5 $\times 10^{3} \mathrm{CFU} / \mathrm{mL}$.

2.7. Agar Well Diffusion Method. The agar well diffusion method betrothed for the investigation during the examination was customized by W. M. M. Kirby and his coworkers in 1956 at the University Of Washington School Of Medicine. Firstly, spread the inoculum evenly on the surface of solidified medium by means of autoclaved cotton swab in every direction. Ultimately, cork borer no. 4 is subjected to grounding of well in the middle of petri plate having medium and plant macerate was added in the hole with the help of dropper or pipette. The petri plates were sealed with cling film.

Label the plate and this process is repeated three times because of observation recorded in triplicate for accurate readings. When purpose is to record antibacterial potential, then the plates were positioned in incubator for 24 hours at $37 \pm 2^{\circ} \mathrm{C}$ whereas, in the condition of evaluation of antifungal potential, the plates were positioned for 48 hours at $25 \pm 2^{\circ} \mathrm{C}$ and solvents employed for maceration process utilized as negative control.

2.7.1. Measurement of Zone of Inhibition. Dimension of zone was estimated through measuring the diameter of zone via ruler or Vernier caliper which was produced as a result of restricting the growth of microbes around plant macerate. The back side of petri plate was apprehended few inches left and to authenticate the readings the diameter was noted. Growth extended from disk to margin was estimated as a zone having length of $0 \mathrm{~mm}$.

2.7.2. Estimation of Minimum Inhibitory Concentration (MIC). For the estimation of minimum inhibitory concentration (MIC), the methanolic extracts of Chenopodium ambrosioides L. including bark and fruit were utilized.
2.8. Preparation of Plant Sample. The different concentrations of plant macerate were practiced for MIC that was 10 , $20,30,40,50,60,70,80,90$, and $100 \mathrm{mg} / \mathrm{mL}$.

2.8.1. MIC Assay. The MIC appraisal was followed as reported Murray et al. [9] with slightly altering this technique. According to this technique, two series of test tubes were made. Each series has 10 test tubes. Dilution of plant extracts ranges from 10 to $100 \mathrm{mg} / \mathrm{mL}$ for a single antimicrobial strain. One test tube series was labeled as control whereas other series of test tubes was labeled for the experimental intentions. Then $1 \mu \mathrm{L}$ microbial suspension, $1 \mu \mathrm{L}$ stock plant dilution, $2.5 \mu \mathrm{L}$ medium (nutrient broth for bacteria and malt extract for fungi), and $3 \mathrm{~mL}$ of sterilized water were put in tubes. In the same way, all the series of the test tubes were sustained. Amount of medium and inoculum which was prepared remains constant while changing the concentration of plant extracts and water also poured in same quantity.

The test tubes which were prepared are positioned in the incubator at $37 \pm 2^{\circ} \mathrm{C}$ for 24 hours while in the case of antifungal potential they were incubated at $25 \pm 2^{\circ} \mathrm{C}$ for 48 hours; readings were noted via spectrophotometer at the $595 \mathrm{~nm}$ absorbance.

2.9. Estimation of Antioxidant Activity. Following techniques were used for the estimation antioxidant potential of Chenopodium ambrosioides $\mathrm{L}$.

2.9.1. Estimation of Total Flavonoid Contents (TFC). Determination of total flavonoids contents of plant fractions was reported by Dewanto et al. [10]. We measured $250 \mu \mathrm{L}$ $(500 \mu \mathrm{g} / \mathrm{mL})$ plant dilution, $1250 \mu \mathrm{L}$ distilled water, and $75 \mu \mathrm{L}(5 \%) \mathrm{NaNO}_{2}$ that then were transferred into the test tubes. These test tubes were put in incubator for 5 minutes. Afterward, $150 \mu \mathrm{L} 10 \% \mathrm{AlCl}_{3}$ was added subsequent to the addition of $500 \mu \mathrm{L} .1 \mathrm{M} \mathrm{NaOH}$. Wait for 6 minutes and then add $275 \mu \mathrm{L}$ sterilized water and raise the final volume up to $2.5 \mathrm{~mL}$. Through spectrophotometer, estimation of the flavonoid content was determined at $510 \mathrm{~nm}$.

2.9.2. Estimation of Total Phenolic Contents (TPC). Makkar et al. (1993) [11] proposed the procedure for investigation of total phenolic contents. Weigh $100 \mu \mathrm{g} / \mathrm{mL}$ plant extract, $2.8 \mathrm{~mL}$ of $10 \% \mathrm{Na}_{2} \mathrm{CO}_{3}$, and $0.1 \mathrm{~mL}$ of $2 \mathrm{~N} \mathrm{FC}$ reagent transferred to test tube after being incubated at room temperature for 40 minutes and absorbance was calculated at $725 \mathrm{~nm}$.

2.9.3. DPPH Radical Scavenging Activity. Precisely $1000 \mu \mathrm{L}$ of plant dilution poured into test tube was measured and mixed with $2.5 \mathrm{~mL}$ of DPPH solution which was freshly prepared. The solution which is formed was shaken and permissible to stand at room temperature for 45-60 minutes. After the incubation, DPPH reduced the solution and the changing of colour takes place. The colour was changed from purple to yellow which revealed that the end point of reaction has been reached. After that, the absorbance of solution was noted at the $515 \mathrm{~nm}$ wavelength via spectrophotometer. 
2.9.4. Metal Chelating Activity. Dinis et al. [12] proposed the method for calculating the capacity of plant macerate to chelate iron. Then we measured plant material $(100 \mu \mathrm{L})$, $\mathrm{FeSO}_{4}(50 \mu \mathrm{L})$, and $200 \mu \mathrm{L}$ ferrozine. The mixture was shaken and volume was raised up to $4 \mathrm{~mL}$ with ethanol solution. Dynamically shake the mixture. The mixture kept at room temperature for 10 minutes and at $562 \mathrm{~nm}$ wavelength its values were noted through spectrophotometer.

2.9.5. ABTS ${ }^{+}$Assay. Miller and Rice (1993) firstly developed the $\mathrm{ABTS}^{\circ}$ assay and further improvement was made by Re et al. [13]. The evaluation of antioxidant potential of ABTS $^{\bullet+}$ assay was done as proposed by Re et al. (1991). Absorbance of $\mathrm{ABTS}^{\bullet+}$ solution was adjusted to $0.68-0.72$ at $734 \mathrm{~nm}$ by the addition of PBS buffer and as $A_{0}$ (absorbance of control). For the estimation of antioxidant activity, $2990 \mu \mathrm{L}_{\text {of }} \mathrm{ABTS}^{\bullet+}$ solution was added in $10 \mu \mathrm{L}$ of plant sample in reaction tube, followed by the shaking of mixture, and the change was noted in absorbance after every 1-minute interval for 8 minutes.

2.10. Statistical Analysis of Assessment. All parameters were carried out in the form of triplicates and findings attained were analyzed statistically to conclude the considerable value of analysis.

\section{Results and Discussion}

The method used for the extraction of the compound was measured to be a crucial factor because different parameters were considered in this regard, that is, commercial viability, extraction yield, and its quality. The technique which is used for this research was maceration of plants because it provides remarkable percentage extraction and it is more cost effective than other techniques [14]. The highest yield was obtained from bark of C. ambrosioides L., that is, $15.45 \%$ (Figure 2). The similar results had been shown by Ajaib et al. [2] when investigating Notholirion thomsonianum. The difference in percentage extraction yield is because of two reasons. First of all, the \% extraction yield increases progressively alongside with the increase in the solvents' polarity; that is, the \% extraction yield has directly proportional relation to the solvents' polarity index. Secondly, special compounds at hand in the plant matter were soluble in their distinctive solvents and the division of the components was potholed in the various parts of the plant [14].

Four bacterial strains including two gram-positive (Staphylococcus aureus, Bacillus subtilis) and two gramnegative (Escherichia coli, Pseudomonas aeruginosa) were used for the estimation of antimicrobial activity of bark and fruit of Chenopodium ambrosioides L. All of these bacteria were pathogenic. Furthermore, two fungal strains Aspergillus oryzae and Aspergillus niger were selected for antifungal potential.

Standard discs were utilized to find out the receptiveness of the microbial strains used as the test organisms (Tables 1 and 2). According to these standards, the specimens were classified as susceptible, intermediate, and resistantsusceptible.

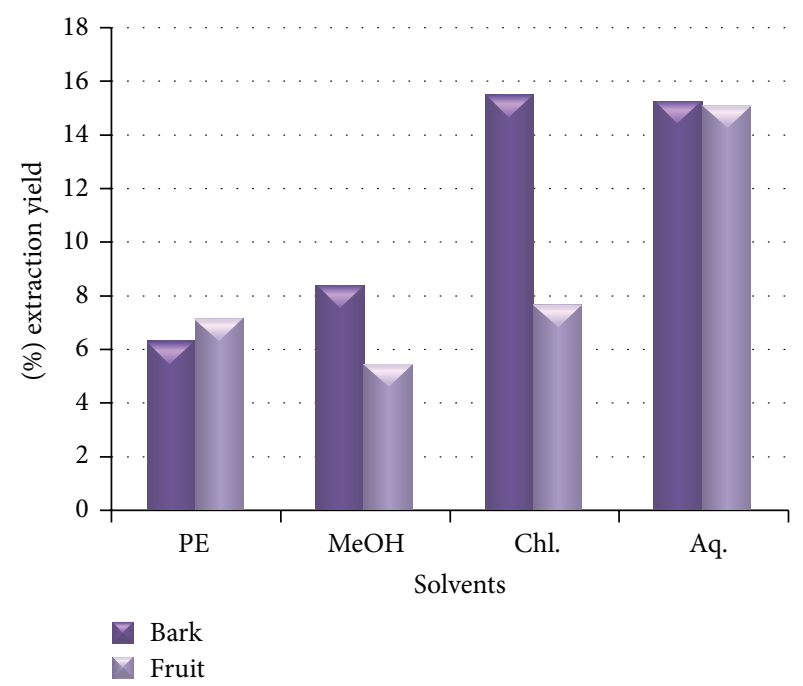

Figure 2: Percentage yield of different parts of C. ambrosioides.

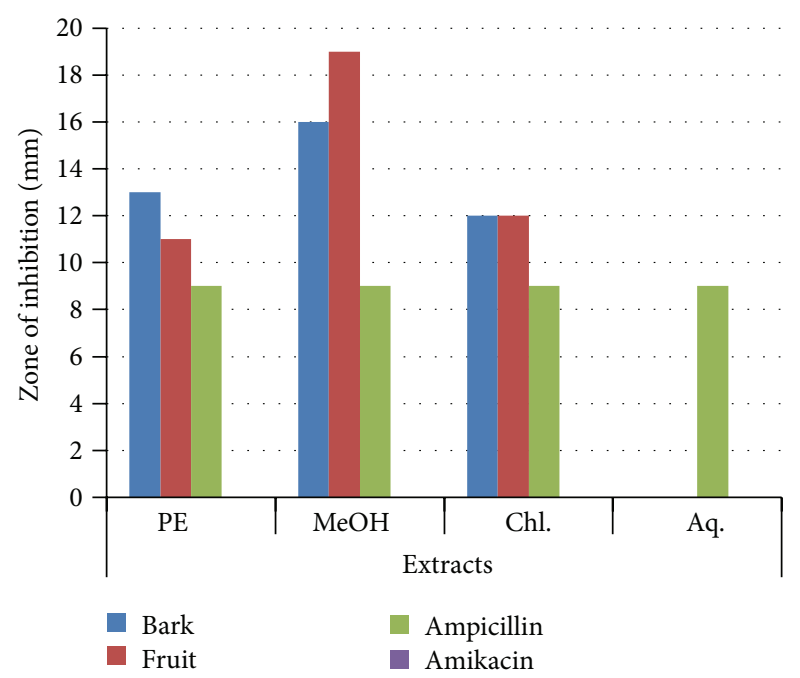

FIGURE 3: Zone of inhibition produced by different parts of ambrosioides against $E$. coli.

Methanol extract of fruit had exhibited maximum potential as compared to bark of methanol extract. Differing from methanol results, petroleum ether bark showed better antimicrobial potential as compared to fruit. The chloroform extract of both parts of both parts had displayed somewhat similar potential, that is, $12 \pm 1.5$ and $12 \pm 1$. The minimum potential is showed by aqueous extracts of both parts. Aqueous extracts failed to show any activity against E. coli (Table 3; Figure 3).

The maximum potential is exhibited by methanol bark extract as compared to methanol fruit extract. Similarly, bark extract of petroleum ether showed good potential compared to petroleum ether fruit extract. Chloroform extract of both parts exhibited close antibacterial potential, that is, $14 \pm 1$ and $15 \pm 1$. The minimum potential was showed by aqueous extracts of both parts. Aqueous extracts failed to show any activity against $S$. aureus (Table 4; Figure 4). 
TABLE 1: Zone of inhibition $(\mathrm{mm})$ produced by the bacterial strains against standard antibiotic discs.

\begin{tabular}{|c|c|c|c|c|c|}
\hline \multirow{2}{*}{ Antibiotic standard disc } & \multirow{2}{*}{ Conc. $(\mu \mathrm{g})$} & \multicolumn{4}{|c|}{ Zone of inhibition (mm) } \\
\hline & & S. aureus & E. coli & $P$. aeruginosa & B. subtilis \\
\hline Azithromycin & 15 & $16 \pm 2.5$ & $15 \pm 1.0$ & $10 \pm 0.6$ & $22 \pm 0.6$ \\
\hline Piperacillin & 15 & - & $30 \pm 1.2$ & $20 \pm 0.4$ & - \\
\hline Amoxicillin & 20 & $12 \pm 1.2$ & $25 \pm 1.0$ & $0 \pm 0$ & $10 \pm 0.2$ \\
\hline Ampicillin & 10 & $8 \pm 1.7$ & $9 \pm 2.0$ & - & - \\
\hline Ceftazidime & 30 & $8 \pm 0.6$ & $20 \pm 1.0$ & $0 \pm 0$ & - \\
\hline Cefotaxime & 10 & $35 \pm 2.5$ & $13 \pm 1.7$ & $0 \pm 0$ & $8 \pm 0.2$ \\
\hline Amikacin & 30 & $18 \pm 0.8$ & - & $21 \pm 1.0$ & - \\
\hline Final response & & Resistant-susceptible & Intermediate-susceptible & Susceptible & Resistant-susceptible \\
\hline
\end{tabular}

TABLE 2: Zone of inhibition $(\mathrm{mm})$ of fungal strains against the standard antifungal discs.

\begin{tabular}{lccc}
\hline $\begin{array}{l}\text { Antifungal } \\
\text { standard disc }\end{array}$ & $\begin{array}{c}\text { Conc. } \\
(\mu \mathrm{g} / \mathrm{mL})\end{array}$ & \multicolumn{2}{c}{ Zone of inhibition $(\mathrm{mm})$} \\
A. niger & A. oryzae \\
\hline Nystatin & 100 & $24 \pm 2.0$ & $32 \pm 1.5$ \\
Tezole & 100 & $22 \pm 0.5$ & $69 \pm 2.9$ \\
Fungivin & 100 & $15 \pm 3.4$ & $42 \pm 1.7$ \\
Griseofulvin & 100 & $22 \pm 0.5$ & $27 \pm 0.5$ \\
\hline Final response & & Intermediate & Intermediate
\end{tabular}

TABLE 3: Zone of inhibition produced by extracts of different parts of $C$. ambrosioides against $E$. coli.

\begin{tabular}{lcccc}
\hline \multirow{2}{*}{$\begin{array}{l}\text { Plant } \\
\text { parts }\end{array}$} & Petroleum ether & Methanol & Chloroform & Aqueous \\
\hline Bark & $13 \pm 1$ & $16 \pm 1$ & $12 \pm 1.5$ & $0 \pm 0$ \\
Fruit & $11 \pm 0.5$ & $19 \pm 1$ & $12 \pm 1$ & $0 \pm 0$ \\
LSD & 0.582 & 2.267 & 2.92 & 0 \\
\hline
\end{tabular}

The results reported were run in triplicate and stated as mean \pm standard error. LSD stands for least significant difference.

The extract of bark had exhibited maximum potential against $P$. aeruginosa as compared to the fruit of with the chloroform extract. The petroleum ether extract of fruit exhibited more potential as compared to bark. Methanol extract of both parts possesses same potential, that is, $29 \pm$ 0.5 . The minimum potential was showed by aqueous extracts of both parts. Aqueous extracts failed to show any activity against $P$. aeruginosa (Table 5; Figure 5).

Bark extract of petroleum ether exhibited highest potential as compared to fruit extract. The methanolic extract of fruit had more potential than bark extract. Chloroform extract of bark proved to be more potent than fruit. Aqueous extracts of both parts showed minimum potency. Bark extract of petroleum ether exhibited excellent activity against $B$. subtilis. Aqueous extract of both parts fails to show any activity (Table 6; Figure 6).

Bark extract of chloroform exhibited maximum potential as compared to fruit extract. Contrary to the extract of chloroform, fruit extract is proved to be more efficient than bark macerated in petroleum ether. Methanolic extract of
TABLE 4: Zone of inhibition produced by extracts of different parts of $C$. ambrosioides against $S$. aureus.

\begin{tabular}{lcccc}
\hline \multirow{2}{*}{$\begin{array}{l}\text { Plant } \\
\text { parts }\end{array}$} & Petroleum ether & Methanol & Chloroform & Aqueous \\
\hline Bark & $30 \pm 1$ & $30 \pm 1.5$ & $14 \pm 1$ & $0 \pm 0$ \\
Fruit & $17 \pm 1$ & $19 \pm 1$ & $15 \pm 1$ & $0 \pm 0$ \\
LSD & 2.267 & 2.92 & 2.267 & 0 \\
\hline
\end{tabular}

TABLE 5: Zone of inhibition produced by extracts of different parts of $C$. ambrosioides against $P$. aeruginosa.

\begin{tabular}{lcccc}
\hline Plant & \multicolumn{4}{c}{ Zone of inhibition $(\mathrm{mm})$} \\
parts & Petroleum ether & Methanol & Chloroform & Aqueous \\
\hline Bark & $20 \pm 1.5$ & $29 \pm 0.5$ & $30 \pm 1$ & $0 \pm 0$ \\
Fruit & $28 \pm 1.5$ & $29 \pm 0.5$ & $20 \pm 1.5$ & $0 \pm 0$ \\
LSD & 3.46 & 2.06 & 2.92 & 0 \\
\hline
\end{tabular}

TABLE 6: Zone of inhibition produced by extracts of different parts of C. ambrosioides against B. subtilis.

\begin{tabular}{lcccc}
\hline \multirow{2}{*}{$\begin{array}{l}\text { Plant } \\
\text { parts }\end{array}$} & \multicolumn{4}{c}{ Zone of inhibition (mm) } \\
& Petroleum ether & Methanol & Chloroform & Aqueous \\
\hline Bark & $33 \pm 1.5$ & $15 \pm 1$ & $25 \pm 0.5$ & $0 \pm 0$ \\
Fruit & $28 \pm 0.5$ & $20 \pm 1.5$ & $19 \pm 1$ & $0 \pm 0$ \\
LSD & 3.46 & 2.92 & 0.582 & 0 \\
\hline
\end{tabular}

TABLE 7: Zone of inhibition produced by extracts of different parts of C. ambrosioides against A. oryzae.

\begin{tabular}{lcccc}
\hline \multirow{2}{*}{$\begin{array}{l}\text { Plant } \\
\text { parts }\end{array}$} & Petroleum ether & Methanol & Chloroform & Aqueous \\
\hline Bark & $11 \pm 0.5$ & $15 \pm 1$ & $15 \pm 2$ & $0 \pm 0$ \\
Fruit & $11 \pm 1.5$ & $15 \pm 1.5$ & $14 \pm 2.64$ & $0 \pm 0$ \\
LSD & 2.61 & 2.92 & 5.315 & 0 \\
\hline
\end{tabular}

both parts exhibited somewhat same potential, that is, $15 \pm 1$ and $15 \pm 1.5$. Minimum potential is exhibited by aqueous extracts. Aqueous extract of both parts failed to show any activity (Table 7; Figure 7). 


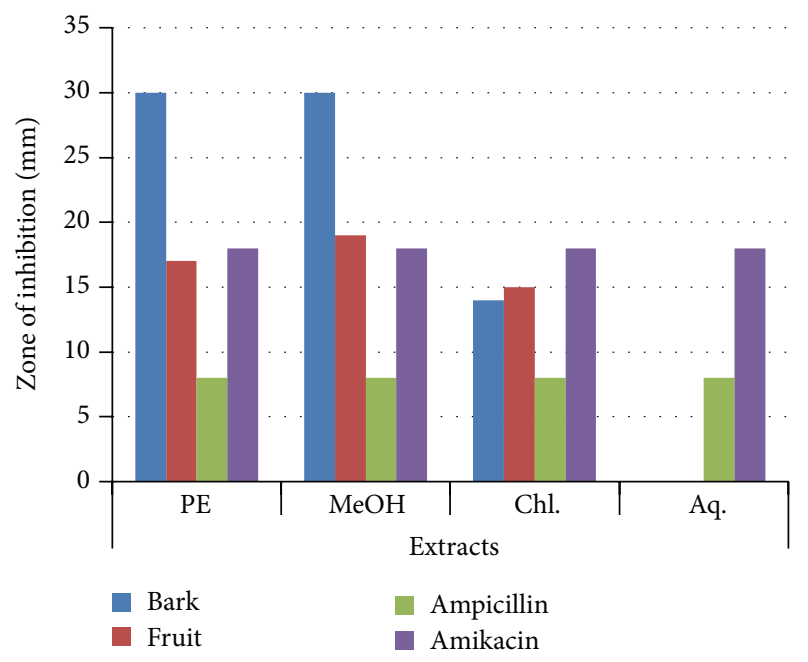

FIgURE 4: Zone of inhibition produced by different parts of $C$. ambrosioides against $S$. aureus.

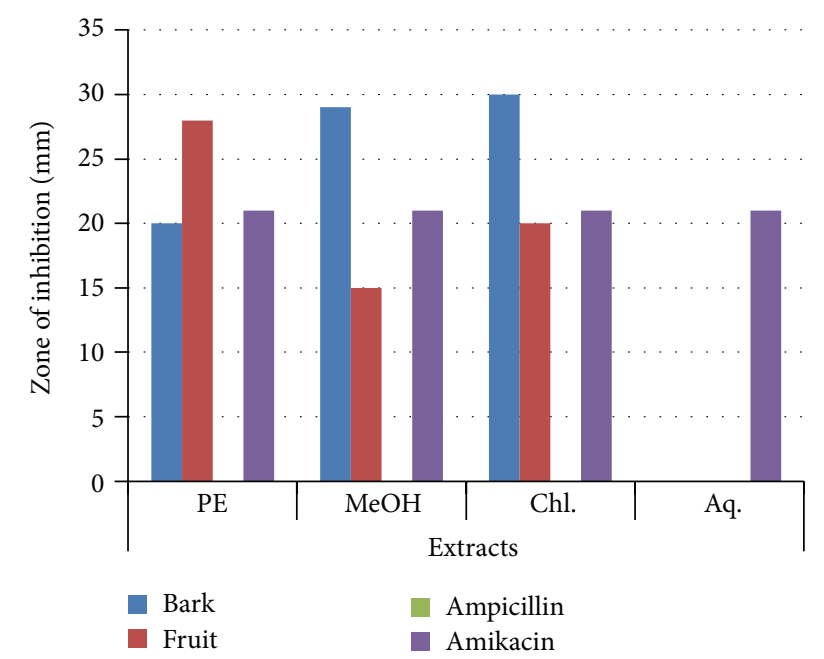

FIGURE 5: Zone of inhibition produced by different parts of $C$. ambrosioides against $P$. aeruginosa.

Fruit extract of methanol exhibited maximum potential as compared to bark. Similarly, fruit extract showed more potential as compared to bark macerated in petroleum ether. Minimum potential is exhibited by aqueous extracts. The fruit extract showed good activity against $A$. niger. Aqueous extract of both parts failed to show any activity (Table 8; Figure 8).

The potential of Chenopodium ambrosioides L. against bacterial strains was $B$. subtilis $>S$. aureus $>P$. aeruginosa $>E$. coli. The antimycotic potential of $C$. ambrosioides $\mathrm{L}$. against fungal strain was $A$. oryzae $>A$. niger (Figure 10). All extracts showed good to satisfactory results against bacterial and fungal strains. Methanolic extracts showed maximum potential as compared to other extracts against both grampositive and gram-negative bacteria (Figure 11).

Minimum inhibitory concentration was carried out through broth agar dilution method. Following this technique 10 dilutions were prepared against all selected bacterial

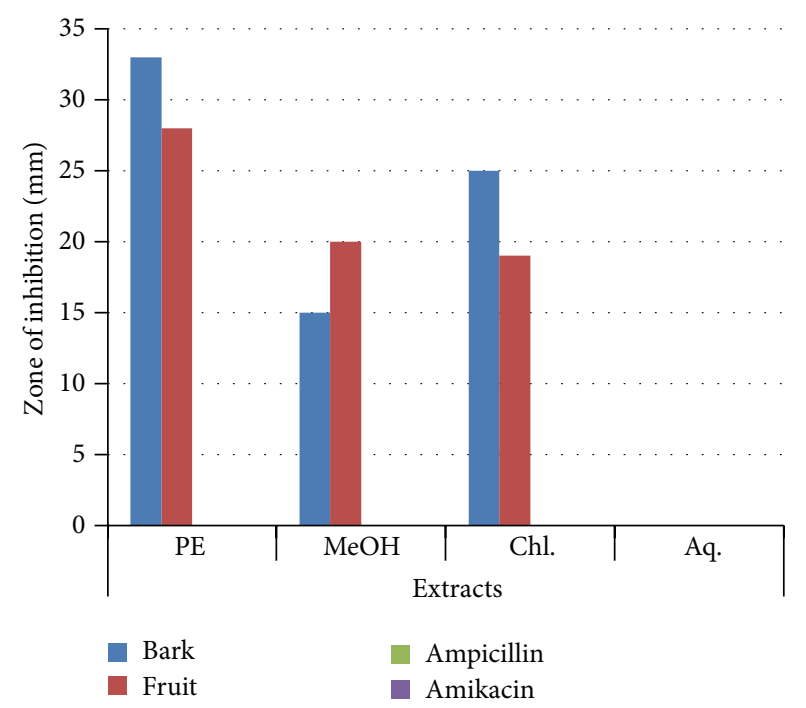

FIGURE 6: Zone of inhibition produced by different part of $C$. ambrosioides against B. subtilis.

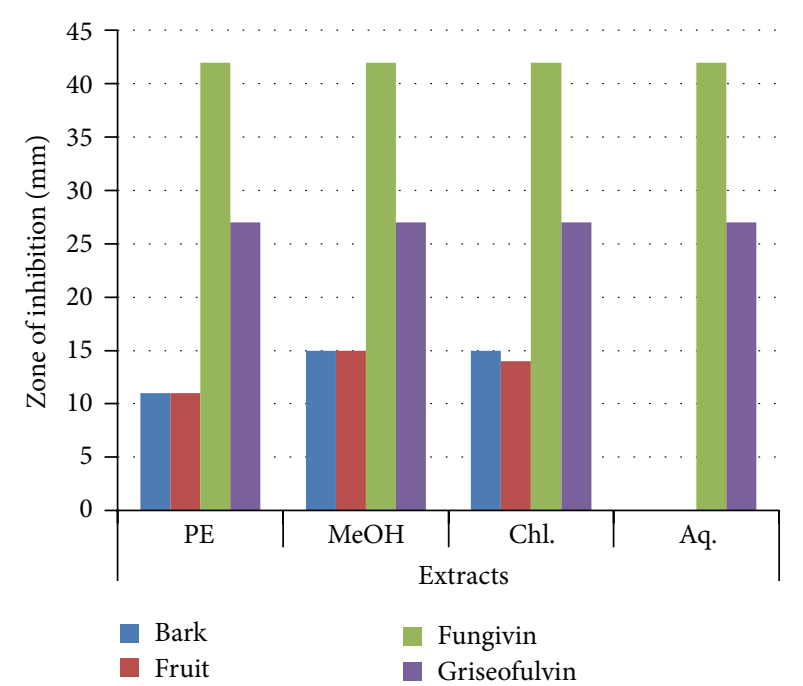

Figure 7: Zone of inhibition produced by different parts of $C$. ambrosioides against $A$. oryzae.

TABLE 8: Zone of inhibition produced by extracts of different parts of C. ambrosioides against A. niger.

\begin{tabular}{lcccc}
\hline \multirow{2}{*}{$\begin{array}{l}\text { lant } \\
\text { parts }\end{array}$} & Petroleum ether & Methanol & Chloroform & Aqueous \\
\hline Bark & $10 \pm 0.57$ & $12 \pm 1$ & $13 \pm 1.5$ & $0 \pm 0$ \\
Fruit & $11 \pm 1$ & $16 \pm 1.5$ & $11 \pm 0.5$ & $0 \pm 0$ \\
LSD & 0.582 & 2.92 & 4.336 & 0 \\
\hline
\end{tabular}

selected strains and minimum concentration achieved which restrict the growth of bacteria at that concentration. Bark possesses $0.043 \pm 0.01$ at $0.8 \mathrm{mg} / \mathrm{mL}$ against $P$. aeruginosa which was minimum amongst all bacterial strains. Fruit possesses $0.009 \pm 0.02$ at $0.7 \mathrm{mg} / \mathrm{mL}$ concentration against 


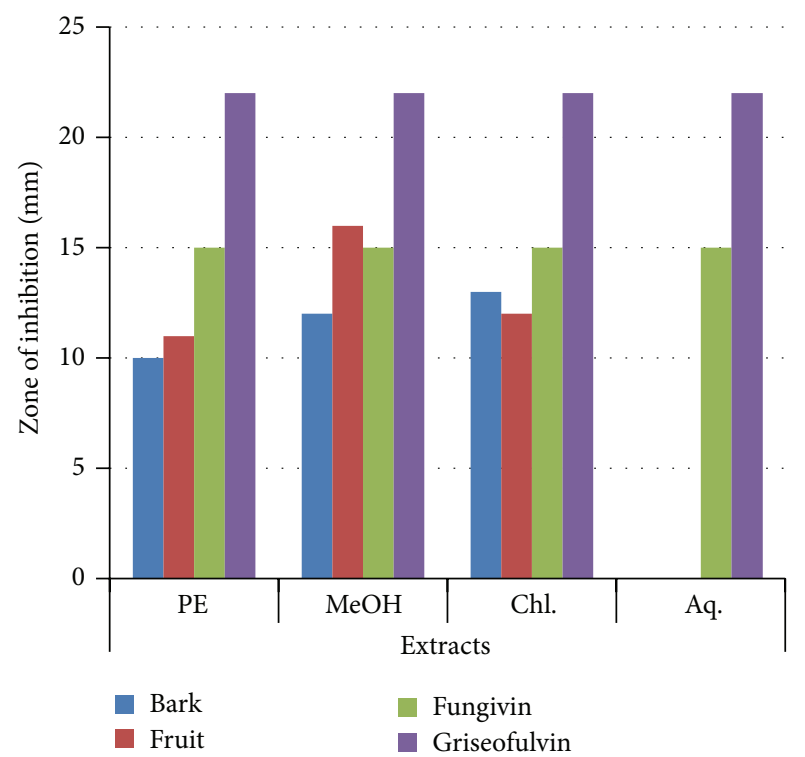

FIGURE 8: Zone of inhibition produced by different parts of $C$. ambrosioides against $A$. niger.

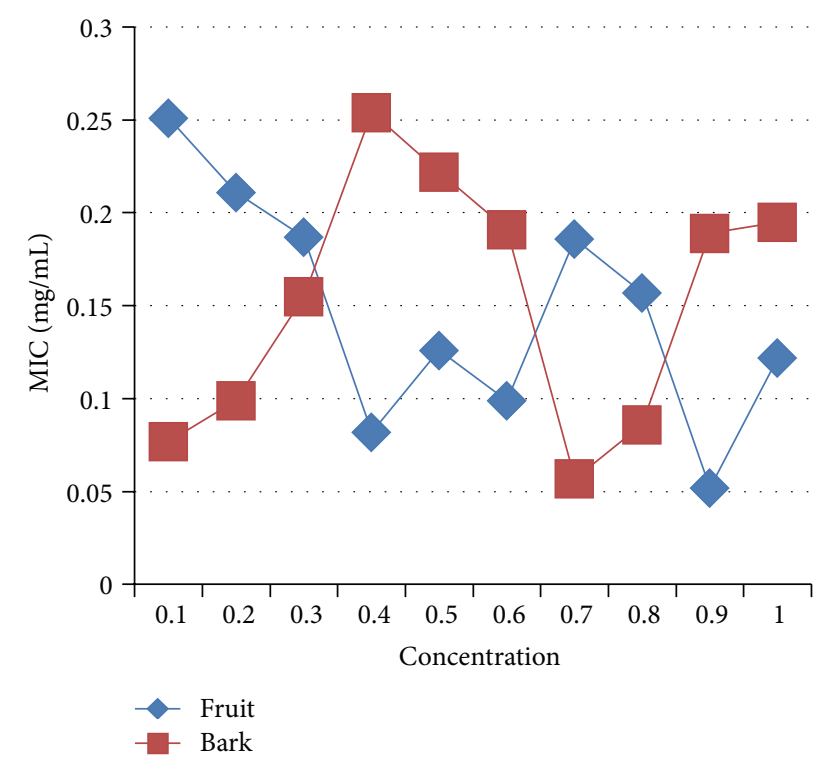

Figure 9: MIC values (mg/mL) exhibiting potential of bark and fruit of $C$. ambrosioides against $E$. coli.

S. aureus. Bark and fruit extracts seem to be more effective against $S$. aureus amongst all bacterial strains (Figure 12).

Dilutions were also made against fungal strains. Bark possesses $0.043 \pm 0.01$ at $1 \mathrm{mg} / \mathrm{mL}$ concentration against $A$. oryzae which was more efficient than $A$. niger. Fruit exhibited $0.054 \pm 0.01$ against $A$. niger at $0.8 \mathrm{mg} / \mathrm{mL}$ concentration. Bark proved to be more competent against $A$. oryzae whereas fruit extract proved more competent against $A$. niger (Figures 13 and 14).

The antioxidant activity was determined by using five assays TPC, TFC, ABTS, metal chelating activity, and DPPH.

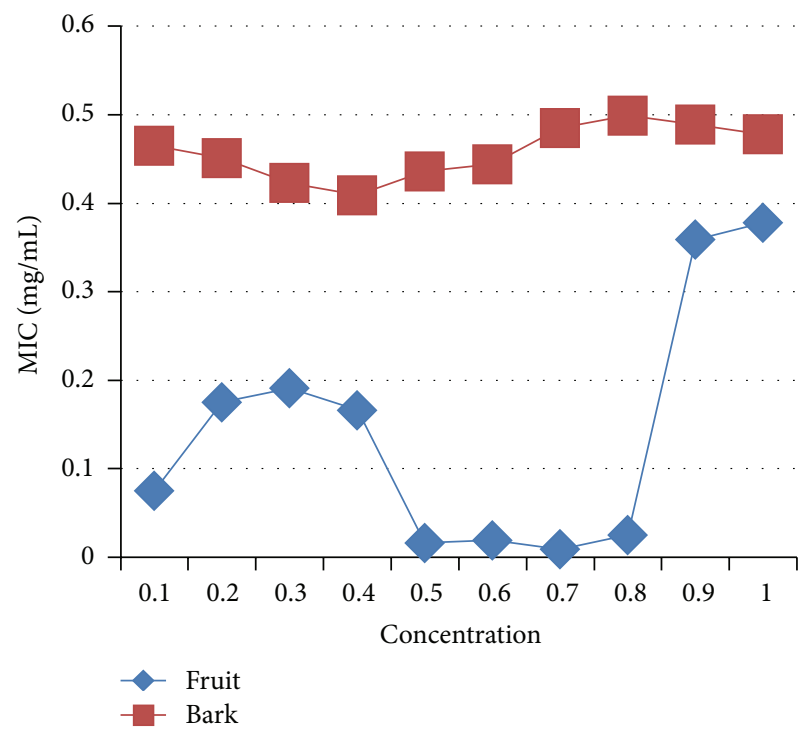

FIGURE 10: MIC values $(\mathrm{mg} / \mathrm{mL})$ exhibiting potential of bark and fruit of $C$. ambrosioides against $S$. aureus.

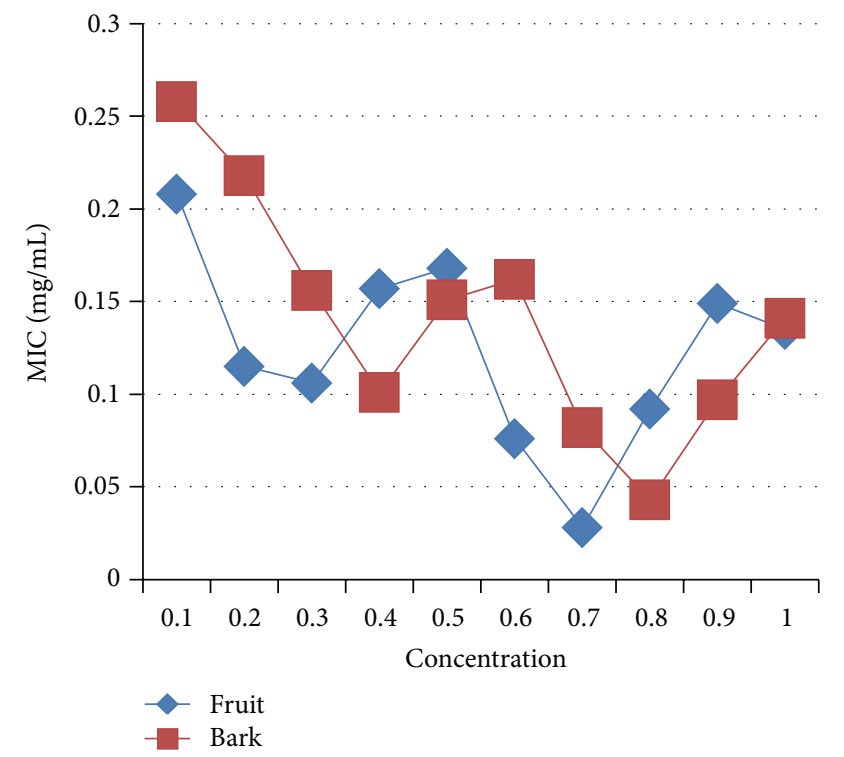

FIGURE 11: MIC values ( $\mathrm{mg} / \mathrm{mL}$ ) exhibiting potential of bark and fruit of C. ambrosioides against $P$. aeruginosa.

Antioxidant compounds obtained from plants were documented as free radicals. Trend has been changed significantly, as there is increased consideration to explore natural possessions having antioxidant potential and can substitute synthetic antioxidants [2].

Aqueous extract of fruit had exhibited maximum potential compared to aqueous extract of bark. Petroleum ether bark extract had more potential as compared to fruit extract. Fruit had exhibited more potential than bark macerated in methanol. Differing from methanol results, bark of chloroform extract showed more gallic acid equivalent $(\mu \mathrm{g} / \mathrm{mL})$ than of fruit. Highest gallic acid equivalent $(\mu \mathrm{g} / \mathrm{mL})$ value is exhibited by fruit aqueous extract, that is, $1076 \pm 0.3 \mu \mathrm{g} / \mathrm{mL}$. 


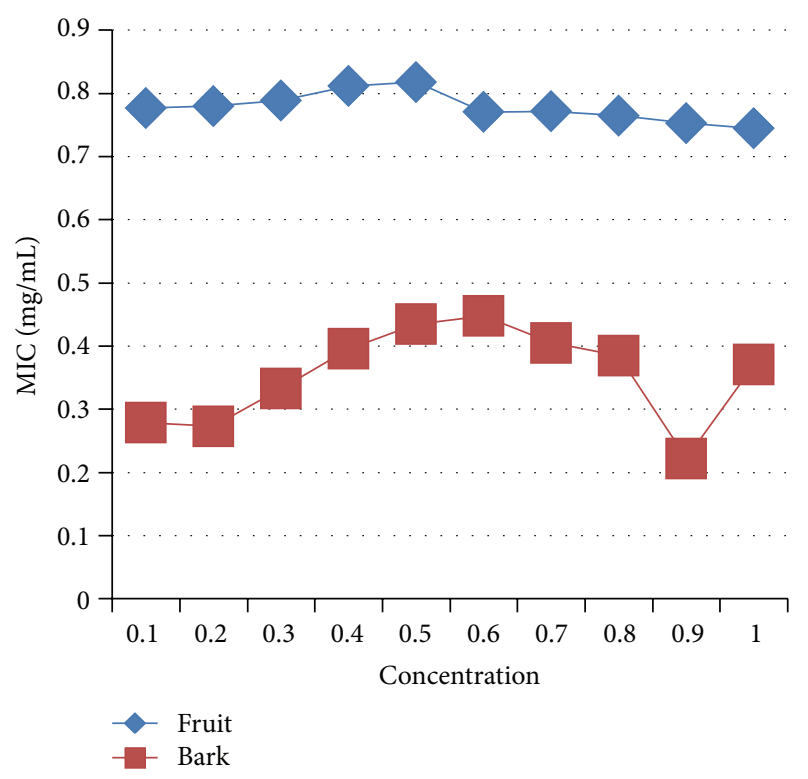

Figure 12: MIC values (mg/mL) exhibiting potential of bark and fruit of C. ambrosioides against B. subtilis.

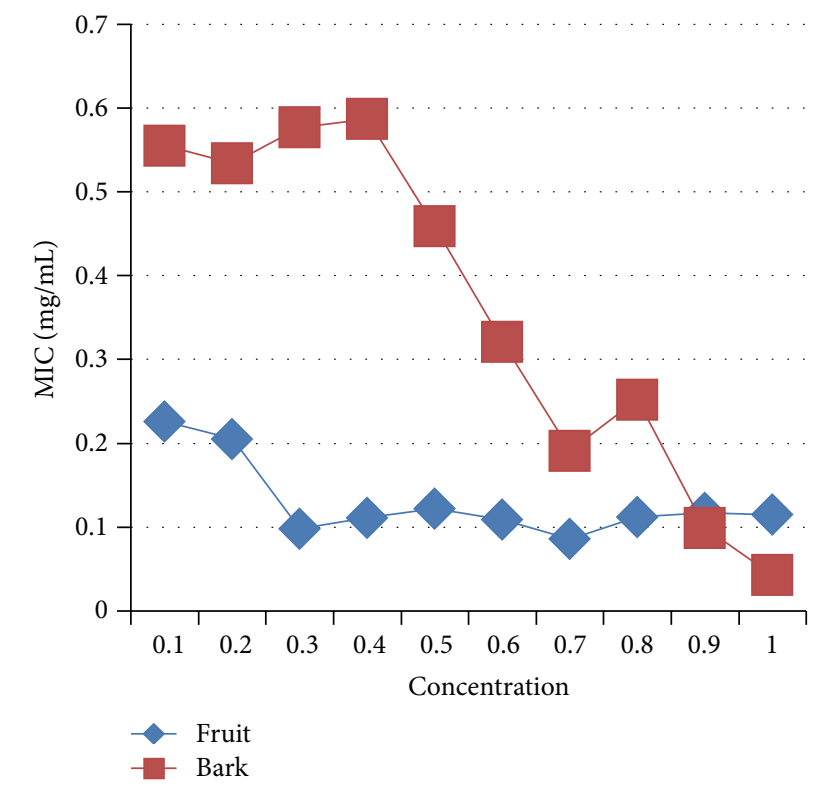

Figure 13: MIC values $(\mathrm{mg} / \mathrm{mL})$ exhibiting potential of bark and fruit of C. ambrosioides against A. oryzae.

The values showed presence of total phenolic contents in both parts of plant (Figure 15).

Maximum potential is exhibited by bark extract as compared to fruit macerated in distilled water. Following aqueous extract, all bark extracts had exhibited more catechin $(\mu \mathrm{g} / \mathrm{mL})$ values as compared to fruit extracts. Highest amount of flavonoid contents was present in aqueous bark extract, that is, $1997.09 \pm 1.5 \mu \mathrm{g} / \mathrm{mL}$, whereas petroleum ether fruit extract possesses minimum catechin value, that is, $714.36 \pm$ $0.2 \mu \mathrm{g} / \mathrm{mL}$. Bark of C. ambrosioides L. proved to be more

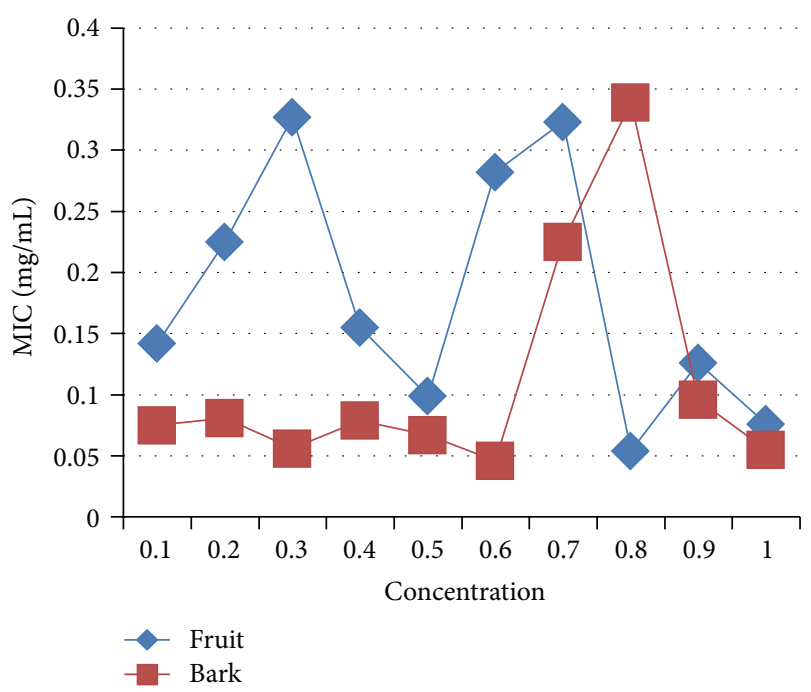

FIGURE 14: MIC values $(\mathrm{mg} / \mathrm{mL})$ exhibiting potential of the bark and fruit of C. ambrosioides against A. niger.

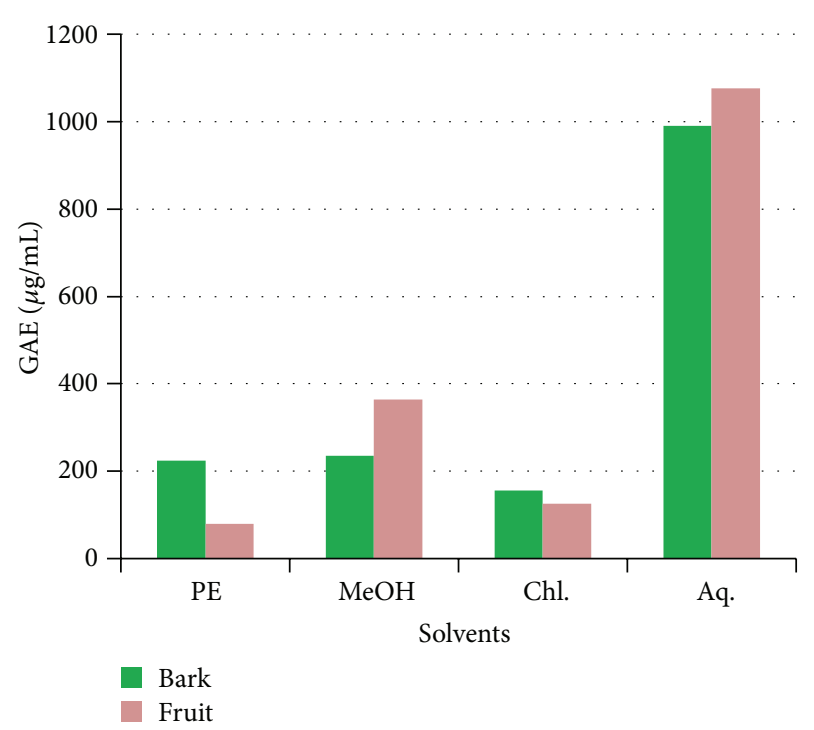

Figure 15: Total phenolic contents (TPC) of different parts of $C$. ambrosioides.

efficient than that of fruit. The highest peak is also depicted by aqueous extract of bark (Figure 16).

Aqueous bark extract exhibited maximum TEAC value $(\mathrm{mM})$ as compared to fruit extract. Similarly, bark extract of petroleum ether and methanol had exhibited more potential than fruit extract whereas chloroform extract of fruit proved to be more efficient than that of chloroform extract of bark. The maximum TEAC value is exhibited by aqueous extract of bark, that is, $10.22 \pm 0.9 \mathrm{mM}$ and $5.21 \pm 0.6 \mathrm{mM}$ minimum TEAC value which was exhibited by petroleum ether fruit extract. The highest and lowest peak are depicted by aqueous extract of bark and petroleum ether fruit extract correspondingly (Figure 17). 


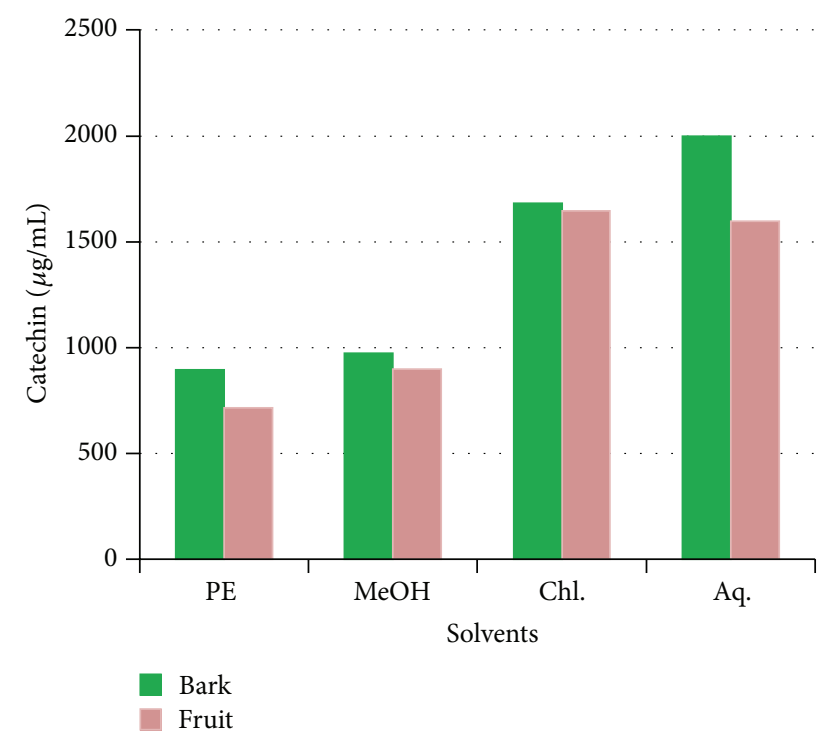

Figure 16: Total flavonoids content (TFC) of different parts of $C$. ambrosioides.

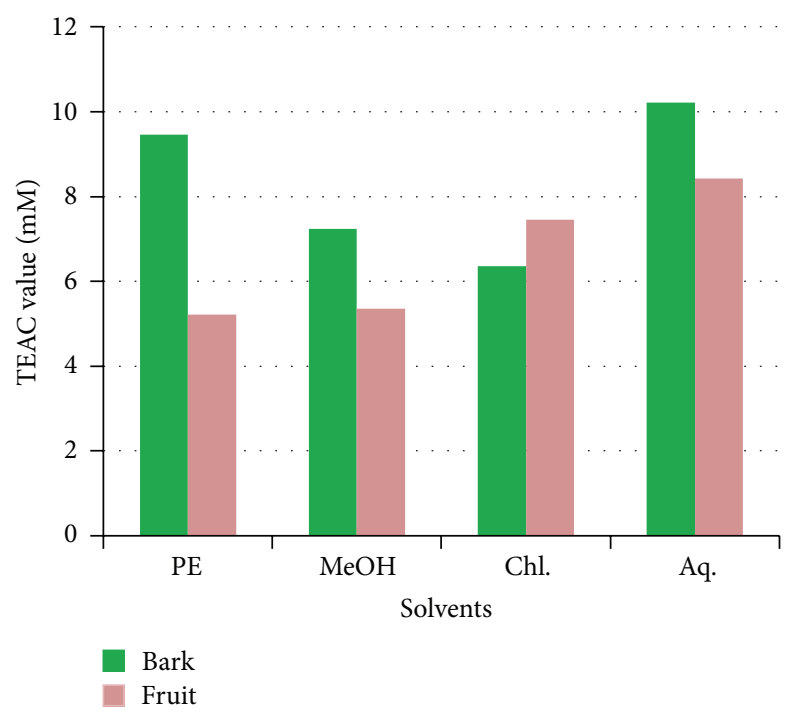

FIgURE 17: ABTS activity of different parts of C. ambrosioides.

Aqueous extract of fruit had exhibited maximum percentage (\%) bound iron as compared to fruit extract. Following aqueous extract, petroleum ether and methanol extract of fruit exhibited more percentage (\%) bound iron values than bark extract. Contrary to other extracts, chloroform bark proved to be more efficient than fruit. The maximum \% bound iron is exhibited by aqueous fruit, that is, $76.99 \pm 1.7 \%$, and minimum \% bound iron is showed by fruit chloroform extract, that is, $7.55 \pm 1.2 \%$. The highest peak and lowest peak are depicted by aqueous and chloroform extract of fruit, respectively (Figure 18).

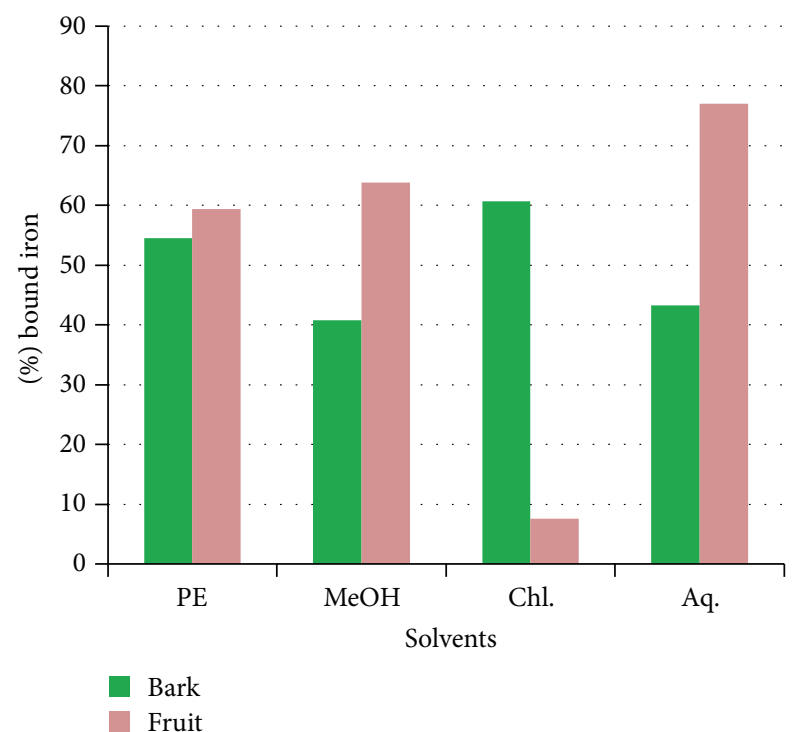

FIGURE 18: Metal chelating activity of different parts of C. ambrosioides.

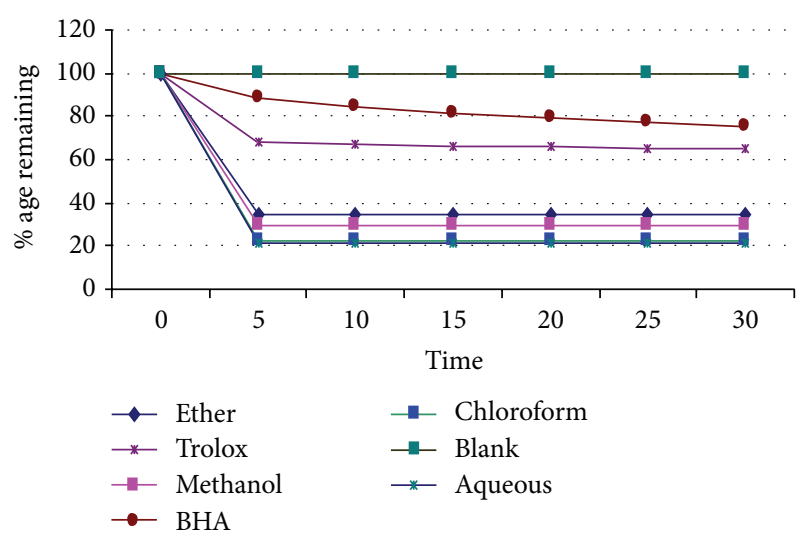

FiguRE 19: DPPH kinetic curve of bark extract of C. ambrosioides.

Bark extract had exhibited maximum \% DPPH (remaining) value compared to fruit macerated with petroleum ether. Following the petroleum ether extract, methanol and aqueous extract of bark had more \% DPPH (remaining) as compared to fruit. Contrary to other extracts, chloroform fruit proved to be more efficient than fruit. The highest $\%$ DPPH (remaining) is showed by petroleum ether bark extract, that is, $34.1 \%$, and minimum value is exhibited by fruit petroleum ether extract, that is, $17.4 \%$ (Figures 19 and 20).

\section{Conclusions}

The assessment of antimicrobial activity exhibited that both parts have maximum to minimum activity against bacterial strains (Figures 21-26). Minimum potential is showed by aqueous extracts of both plants against bacteria. The plants also showed good to satisfactory potential against fungal strains but both plants had more antibacterial potential as 


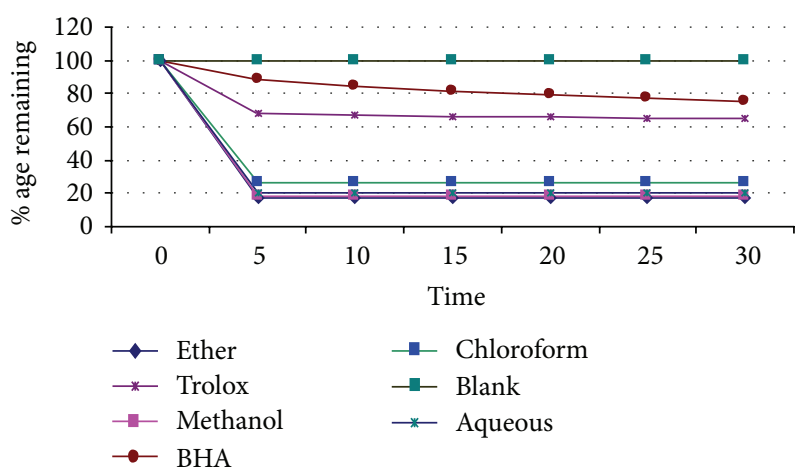

FIGURE 20: DPPH kinetic curve of fruit extract of C. ambrosioides.

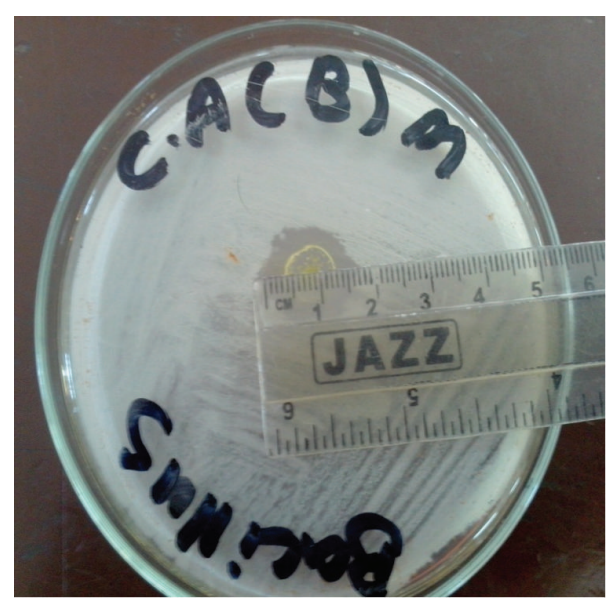

FIgURE 21: Zone of inhibition of methanol extract of bark of $C$. ambrosioides L. against B. subtilis.

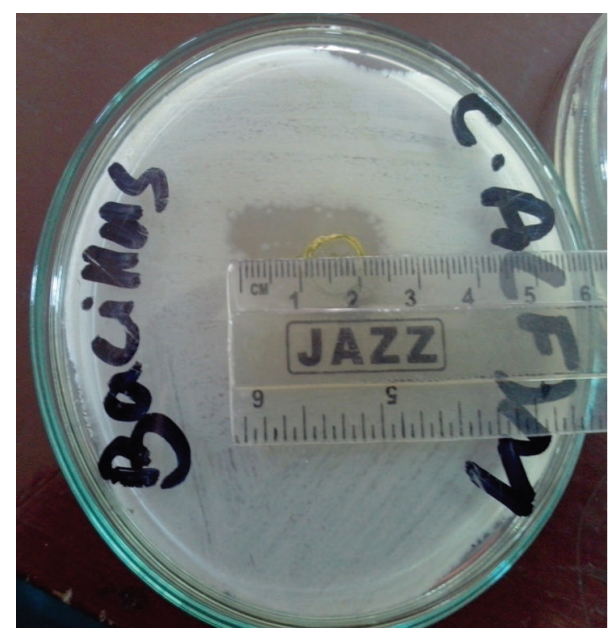

Figure 22: Zone of inhibition of methanol extract of fruit of $C$. ambrosioides L. against B. subtilis.

compared to antifungal. The antioxidant activity revealed that both plants show good potential for TPC, TFC, DPPH, and ABTS assay and metal chelating. The aqueous extract of both parts of selected plant exhibited significant response for TPC, TFC, and metal chelating whereas methanol depicted good response to ABTS assay; aqueous and petroleum ether

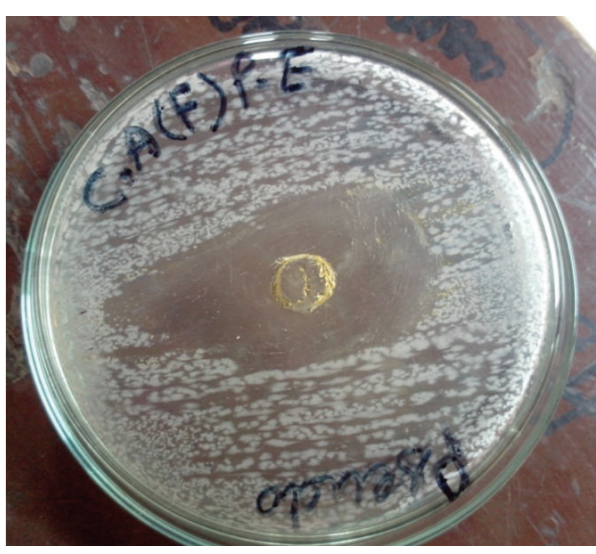

FIgURE 23: Zone of inhibition of petroleum ether extract of fruit of C. ambrosioides $\mathrm{L}$. against $P$. aeruginosa.

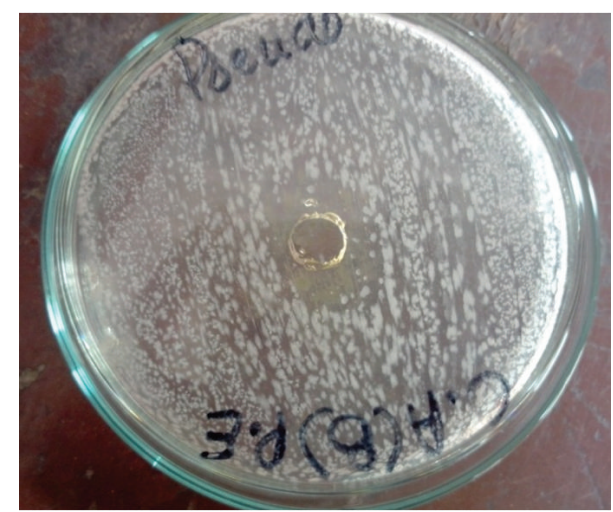

FIgURE 24: Zone of inhibition of petroleum ether extract of bark of C. ambrosioides L. against $P$. aeruginosa.

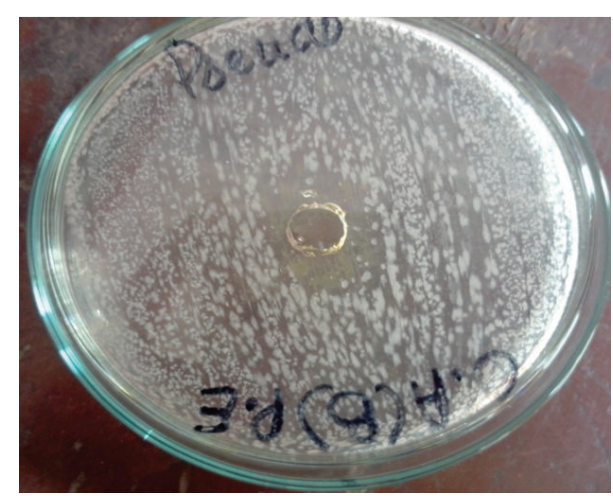

FIgURE 25: Zone of inhibition of petroleum ether extract of bark of C. ambrosioides $\mathrm{L}$. against $P$. aeruginosa.

extract have shown good potency for DPPH. The result indicated good antimicrobial and antioxidant potential and further studies of C. ambrosioides $\mathrm{L}$ might reveal some new bioactive compounds that would make contribution to the ethnopharmacology. 


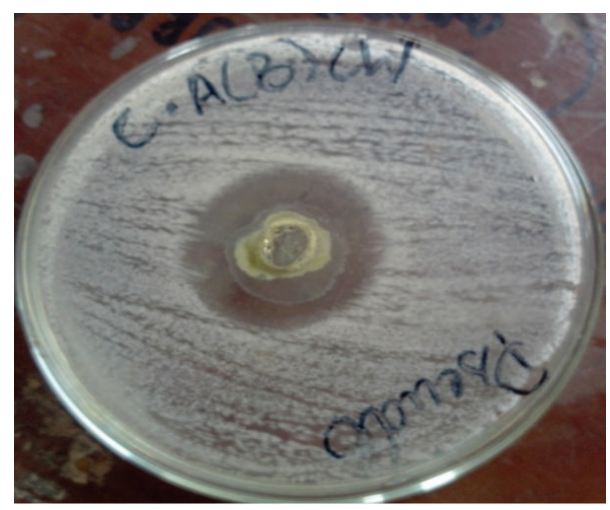

Figure 26: Zone of inhibition of chloroform extract of bark of $C$. ambrosioides L. against $P$. aeruginosa.

\section{Competing Interests}

The authors declare no conflict of interest.

\section{References}

[1] F. Mazhar, R. Khanum, M. Ajaib, and M. Jahangir, "Potent AChE enzyme inhibition activity of Zizyphus oxyphylla: a new source of antioxidant compounds," Pakistan Journal of Pharmaceutical Sciences, vol. 28, no. 6, pp. 2053-2059, 2015.

[2] M. Ajaib, S. Ali, and Z. Khan, "Antioxidant and antimicrobial activities of an ethnobotanically important plant Notholirion thomsonianum from district Kotli, Azad Jammu \& Kashmir," Journal of Animal and Plant Sciences, vol. 24, no. 3, pp. 774-780, 2014.

[3] M. Ajaib, Z. Khan, M. A. Abbasi, and T. Riaz, "Antimicrobial screening of Iris aitchisonii (Bakar) Boiss," Biologia, vol. 59, pp. 51-55, 2013

[4] U. Munir, A. Perveen, and S. Qamarunnisa, "Comparative pharmacognostic evaluation of some species of the genera Suaeda and Salsola leaf (Chenopodiaceae)," Pakistan Journal of Pharmaceutical Sciences, vol. 27, no. 5, pp. 1309-1315, 2014.

[5] H. Freitag, I. C. Hedge, S. M. H. Jafri, G. Kothe-Heinrich, S. Omer, and P. Uotila, "Flora of Pakistan," in Chenopodiaceae. No. 204, S. I. Ali and M. Qaiser, Eds., Department of Botany, University of Karachi, Karachi, Pakistan, 2001.

[6] M. Ajaib, Exploration of floral diversity of district Kotli (Azad Jammu \& Kashmir) and evaluation of ethnopharmacological effects of some medicinal plants of the area [Ph.D. thesis], Department of Botany, GC University, Lahore, Pakistan, 2012.

[7] R. Cruick-Shank, J. P. Dugid, B. P. Marinionon, and R. H. A. Swain, "Screening of some greek aromatic plants for antioxidant activity," Phytotherapy Research, vol. 17, pp. 194-195, 1975.

[8] D. A. Johansen, Plant Microtechnique, McGraw-Hill, New York, NY, USA, 1940.

[9] P. R. Murray, E. J. Baron, M. A. Pfaller, F. C. Tenover, and R. H. Yolke, Manual of Clinical Microbiology, American Society for Microbiology (ASM), Washington, DC, USA, 7th edition, 1999.

[10] V. Dewanto, X. Wu, K. K. Adom, and R. H. Liu, "Thermal processing enhances the nutritional value of tomatoes by increasing total antioxidant activity," Journal of Agricultural and Food Chemistry, vol. 50, no. 10, pp. 3010-3014, 2002.
[11] H. P. S. Makkar, M. Blümmel, N. K. Borowy, and K. Becker, "Gravimetric determination of tannins and their correlations with chemical and protein precipitation methods," Journal of the Science of Food and Agriculture, vol. 61, no. 2, pp. 161-165, 1993.

[12] T. C. P. Dinis, V. M. C. Madeira, and M. L. M. Almeida, "Action of phenolic derivates (acetoaminophen, salycilate and 5aminosalycilate) as inhibitors of membrane lipid peroxidation and as peroxyl radical scavengers," Archives of Biochemistry and Biophysics, vol. 315, no. 1, pp. 161-169, 1994.

[13] R. Re, N. Pellegrini, A. Proteggente, A. Pannala, M. Yang, and C. Rice-Evans, "Antioxidant activity applying an improved ABTS radical cation decolorization assay," Free Radical Biology and Medicine, vol. 26, no. 9-10, pp. 1231-1237, 1999.

[14] M. Ajaib, S. Q. Wahla, K. M. Khan, S. Perveen, and S. Shah, "Firmiana simplex: a potential source of antimicrobials," Journal of the Chemical Society of Pakistan, vol. 36, no. 4, pp. 744-752, 2014. 

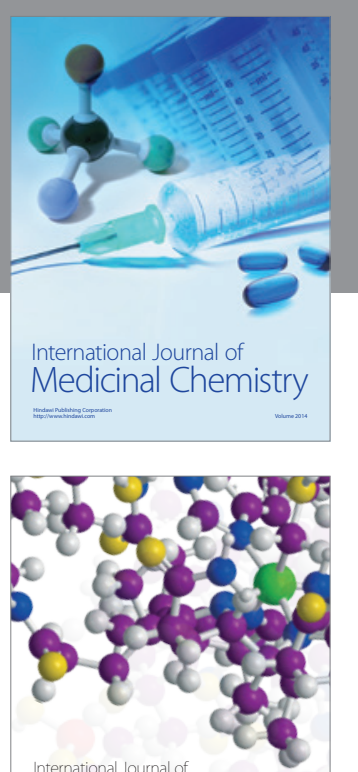

Carbohydrate Chemistry

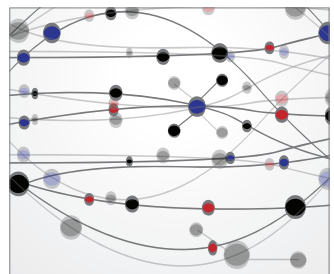

The Scientific World Journal
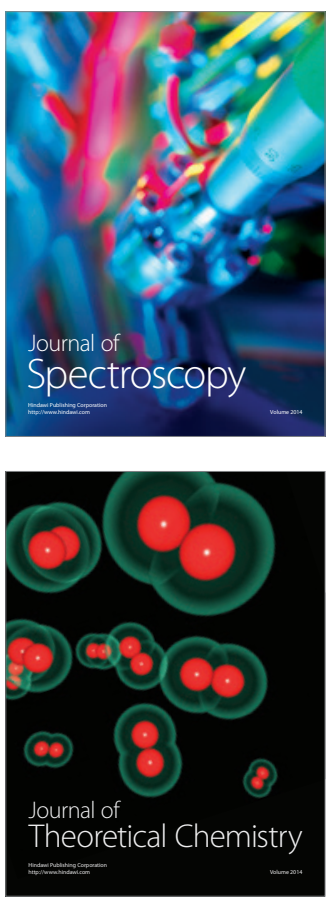
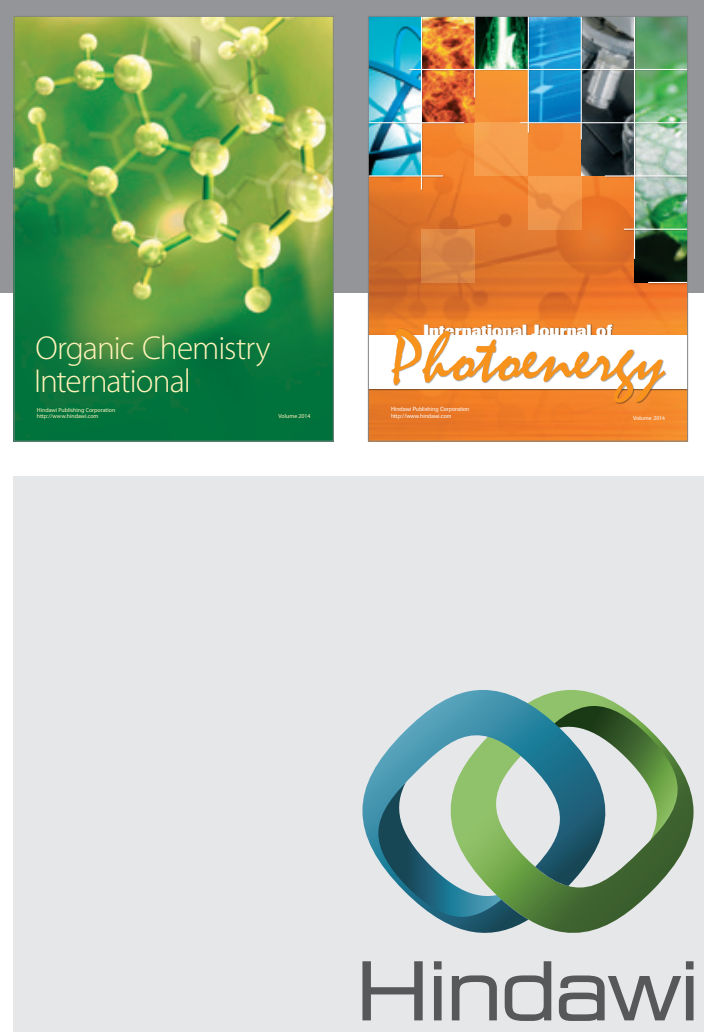

Submit your manuscripts at

http://www.hindawi.com

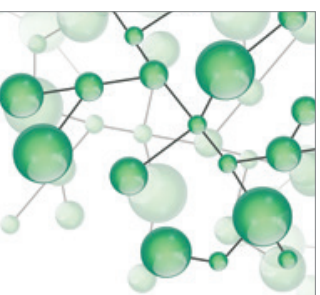

International Journal of

Inorganic Chemistry

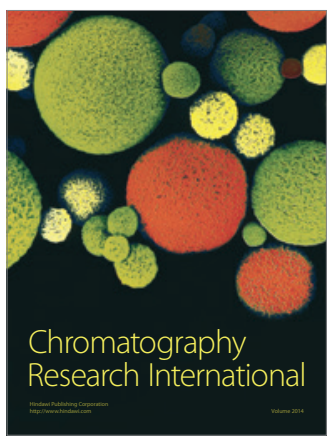

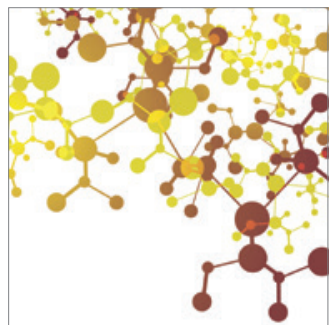

Applied Chemistry
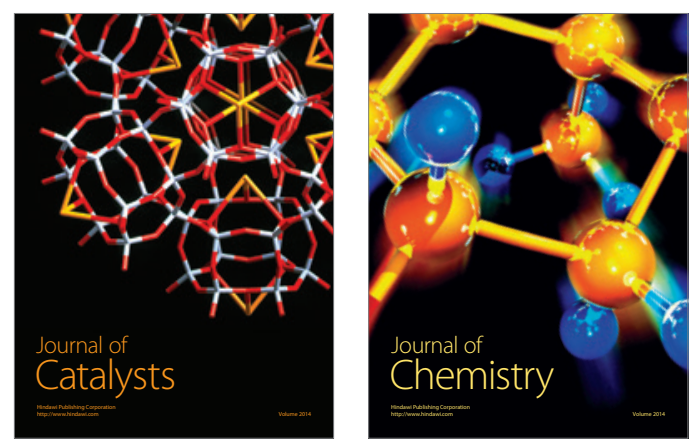
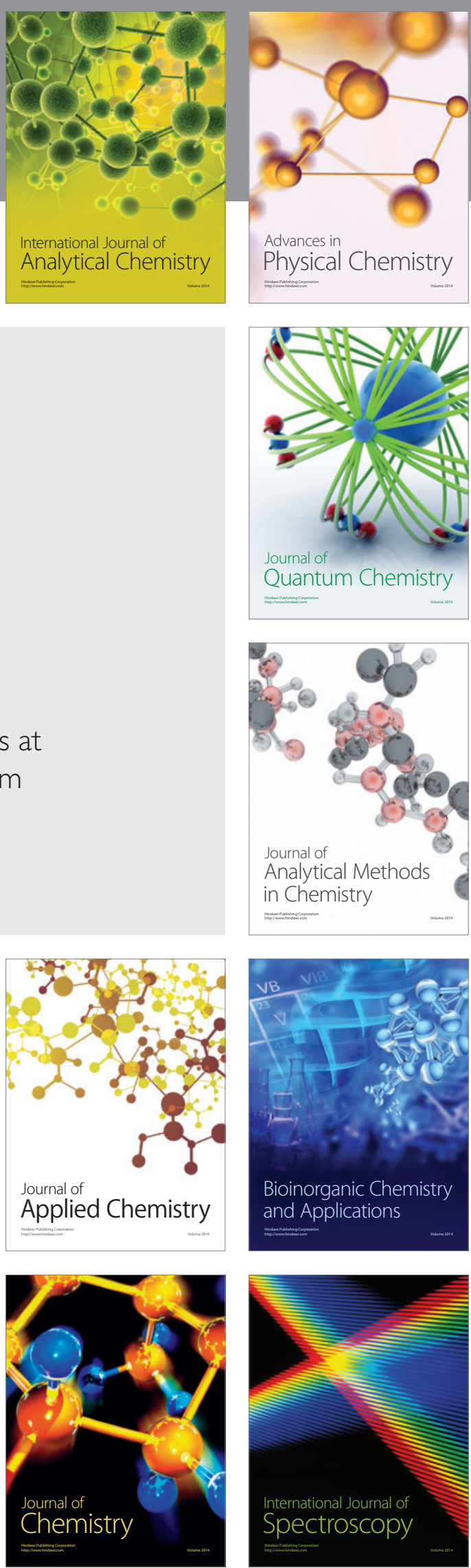